\title{
Vibrational spectra and assignments for $\left(\mathrm{CH}_{3}\right)_{2} \mathrm{NPF}_{2}$
}

\author{
S'tster Mary Atrert Fugmtna, Richard .T. Wyma and Rorert C. Taytor \\ Department of Chemistry, The University of Michigan Ann Arbor, Michigan
}

(Received 24 November 1964)

\begin{abstract}
Infrared and Raman spectra of dimethylaminodifluorophosphine have been obtained for the gaseous and liquid states at room temperature and for the solid at low temperature. Vibrational assignments are proposed based on a $C_{s}$ model.
\end{abstract}

DimethylaMiNODIFLUOROPHOSPHINE is representative of a class of compounds generically related to trifluorophosphine through the replacement of one or more fluorine atoms by amine residues. These substances behave as Lewis bases and exhibit basicities intermediate between those of simple ethers and free amines [1-3]. Coordination compounds of these ligands and transitions metals have been described recently [2] as well as complexes with typical Lewis acids [1, 3]. In the case of dimethylaminodifluorophosphine, evidence has been supplied [1] that coordination may occur either through the nitrogen or phosphorous atom, depending on the nature of the Lewis acid.

No spectroscopic study of $\left(\mathrm{CH}_{3}\right)_{2} \mathrm{NPF}_{2}$ has been published although its principal infrared bands have been reported $[2,3]$; infrared frequencies and qualitative assignments for the chlorine analog have appeared [4]. In the present investigation, infrared spectra of the compound in the gaseous and solid states and Raman spectra of the liquid and solid have been obtained and assignments are proposed.

\section{EXPERIMENTAL}

Dimethylaminodifluorophosphine-This compound was prepared by the direct reaction of dimethylamine and trifluorophosphine under controlled conditions in the vacuum line and given an initial purification by fractionation. This was followed by a second distillation from anhydrous $\mathrm{CoBr}_{2}$ which freed it from traces of $\left(\mathrm{CH}_{3}\right)_{2} \mathrm{NH}$ and bisdimethylaminofluorophosphine. The purified material melted at $-87^{\circ} \mathrm{C}$ and had a vapor pressure of $93.4 \mathrm{~mm}$ at $0^{\circ} \mathrm{C}$. Further characterization of the compound including analytical data, molecular weight and other physical and chemical properties is given in detail elsewhere [1]. Since the compound is decomposed by moisture and contact with strong bases, cells, containers and apparatus with which it came in contact were acidified and then carefully dried to prevent decomposition.

Spectroscopy - For the Raman spectra of the liquid, the material was condensed into capillary cells which were then sealed off. Unless special precautions were taken to eliminate water, the samples developed a slight turbidity or deposited a light sediment after a few hours making it difficult to obtain an intense spectrum free of background. The spectrograph and light source used have been described

[1] Sister M. A. Fleming, G. Kodama and R. W. Parry, to be published.

[2] R. Schmutzler, Inorg. Chem. 3, 415 (1964).

[3] R. C. Cavelu, J. Chem. Soc. 1992 (1964).

[4] R. B. HarveY and J. E. Mayhood, Can. J. Chem. 33, 1552 (1955). 
previously [5]. Solid Raman spectra at approximately $-160^{\circ} \mathrm{C}$ were obtained using an arrangement employing multilayer interference filters patterned somewhat after that described by Schrader [6]. More complete details will be given elsewhere. Frequency measurements were made both on the plates and on tracings, the data listed representing averages from several samples. The estimated probable error of most bands is $2 \mathrm{~cm}^{-1}$ with somewhat larger values for weak bands. Qualitative polarization measurements were made using the two exposure method and polaroid cylinders.

The infrared instruments were Perkin-Elmer Model 21 spectrophotometers equipped with $\mathrm{NaCl}, \mathrm{CaF}_{2}$ or $\mathrm{KBr}$ prisms and calibrated periodically with an indene standard. A standard $10 \mathrm{~cm}$ cell was used for the gas work while the spectra of the solid films at liquid nitrogen temperatures were obtained in a familiar $\mathrm{T}$-shaped cell by depositing the vapor directly on a $\mathrm{KBr}$ window in good thermal contact with a copper block attached to a liquid nitrogen reservoir. Estimated probable errors in the frequencies are of the order of 2 or $3 \mathrm{~cm}^{-1}$ below $2000 \mathrm{~cm}^{-1}$ and of the order of 5 to $8 \mathrm{~cm}^{-1}$ above.

\section{Experimental Results}

The observed infrared and Raman frequencies under the various conditions are tabulated in Table 1 together with approximate intensities, depolarization information

Table 1. Infrared and Raman spectra of $\left(\mathrm{CH}_{3}\right)_{2} \mathrm{NPF}_{2}$

\begin{tabular}{|c|c|c|c|c|}
\hline \multicolumn{2}{|c|}{ Infrared } & \multicolumn{2}{|c|}{ Raman } & \multirow[b]{2}{*}{ Assignment } \\
\hline gas & solid $\left(-190^{\circ}\right)$ & liquid $\left(-30^{\circ}\right)$ & solid $\left(-160^{\circ}\right)$ & \\
\hline & $3002 \mathrm{vw}$ & $2998 \mathrm{~s}, \mathrm{sh}, \mathrm{dp}$ & $2996 \mathrm{~s}$ & $\nu_{17}, \nu_{18}$ \\
\hline $2925 \mathrm{~m}$ & $2932 \mathrm{mw}$ & $2945 \mathrm{vs}, \mathrm{dp}$ & $2935 \mathrm{vs}$ & $\nu_{10}$ \\
\hline & & 2912 va, $p$ ? & $2906 \mathrm{vg}, \mathrm{sh}$ & $v_{1}$ \\
\hline $2865 \mathrm{sh}$ & & $2861 \mathrm{~s}, \mathrm{p}$ & $2867 \mathrm{~s}$ & $v_{2}$ \\
\hline $2820 \mathrm{w}$ & $\begin{array}{l}2817 \mathrm{vw} \\
1498 \mathrm{w}\end{array}$ & $2814 \mathrm{~s}, \mathrm{p}$ & 2815 s & $v_{328}^{v_{3}}+764=1492$ \\
\hline 1507 & $\begin{array}{l}1490 \mathrm{~m} \\
1473 \mathrm{w} \\
1463 \mathrm{w} \\
1455 \mathrm{~m}\end{array}$ & $1487 \mathrm{~m}, \mathrm{dp}$ & $1495 \mathrm{~m}$ & $\begin{array}{l}v_{20} \\
707+764=1471 \\
393+1073=1466 \\
v_{21}\end{array}$ \\
\hline $1432 \mathrm{w}$ & $\begin{array}{l}1443 \mathrm{w} \\
1430 \mathrm{vw}\end{array}$ & $1439 \mathrm{~s}, \mathrm{dp}$ & $1432 \mathrm{~s}$ & $707+728=1435$ \\
\hline $1307 \mathrm{~m}$ & $\begin{array}{l}1313 \mathrm{~s} \\
1233 \mathrm{vw} \\
1206 \mathrm{~m}\end{array}$ & $\begin{array}{l}1414 \mathrm{w}, \mathrm{sh}, \mathrm{dp} ? \\
1306 \mathrm{~m}, \mathrm{p}\end{array}$ & $1315 \mathrm{~m}$ & $\begin{array}{l}v_{4}, v_{5} \\
v_{6} \text { sym. } \mathrm{CH}_{3} \text { deform } \\
499+728=1227 \\
v_{23} ?\end{array}$ \\
\hline $1195 \mathrm{~m}$ & $1191 \mathrm{~s}$ & & & $\begin{array}{l}\nu_{25}\left(\nu_{7}, \nu_{23} ?\right) \\
\quad \text { asym. C-N stretch }\end{array}$ \\
\hline $1073 \mathrm{w}$ & $\begin{array}{l}1073 \mathrm{~m} \\
1002 \mathrm{sh}\end{array}$ & $\begin{array}{l}1103 \mathrm{vw} \\
1071 \mathrm{w}, \mathrm{dp} ?\end{array}$ & $\begin{array}{l}1107 \mathrm{~m} \\
1075 \mathrm{~m}\end{array}$ & $\begin{array}{l}v_{8} \text { or } v_{24} \mathrm{CH}_{3} \text { rock } \\
\nu_{8} \text { or } \nu_{24} \mathrm{CH}_{3} \text { rock } \\
v_{7}, v_{23}\left(\nu_{25} \text { ?) } \mathrm{CH}_{3} \text { rook }\right. \\
2 \times 499=998\end{array}$ \\
\hline 989 s & $994 \mathrm{~s}$ & $989 \mathrm{~m}, \mathrm{dp} ?$ & $999 \mathrm{~m}$ & $v_{9}$ sym. $\mathrm{C}_{2} \mathrm{NP}$ stretch \\
\hline $814 \mathrm{~s}$ & $764 \mathrm{~s}$ & $792 \mathrm{~m}, \mathrm{p}$ ? & $759 \mathrm{~m}$ & $\nu_{26}$ asym. P-F stretch \\
\hline $770 \mathrm{~g}$ & $728 \mathrm{~m}$ & $743 \mathrm{~m}, \mathrm{dp} ?$ & & $\nu_{10}$ sym. P-F stretch \\
\hline $704 \mathrm{~m}$ & $707 \mathrm{vs}$ & $705 \mathrm{vs}, \mathrm{p}$ & $704 \mathrm{~s}$ & $\nu_{11}$ sym. $\mathrm{N}-\mathrm{P}-\mathrm{F}_{2}$ stretch \\
\hline $501 \mathrm{w}, \mathrm{br}$ & $\begin{array}{l}499 \mathrm{w} \\
486 \mathrm{vvw}\end{array}$ & $495 \mathrm{~m}$ & $494 w$ & $\begin{array}{l}y_{12} \text { sym. } \mathrm{PF}_{\mathrm{a}} \text { deform. } \\
\text { skeletal? }\end{array}$ \\
\hline & & $393 \mathrm{w}$ & & $v_{13}$ sym. $\mathrm{NC}_{2}$ deform. \\
\hline & & $336 \mathrm{~m}$ & & $v_{14}$ sym. $\mathrm{NC}_{2}$ rook \\
\hline & & $\begin{array}{l}239 \mathrm{w} \\
173 \mathrm{w}\end{array}$ & & $v_{15}$ or $\nu_{28} ?$ \\
\hline & & $97 \mathrm{vvw}$ & & $\begin{array}{l}\nu_{16} \text { or } v_{28} \\
v_{30} \text { ? }\end{array}$ \\
\hline
\end{tabular}

[5] G. L. Vidale and R. C. Taylor, J. Am. Chem. Soc. 78, 294 (1956).

[6] B. Schrader, F. Nerde, and G. Kresze, Z. Phys. Chem., N. F., 12, 132 (1957). 


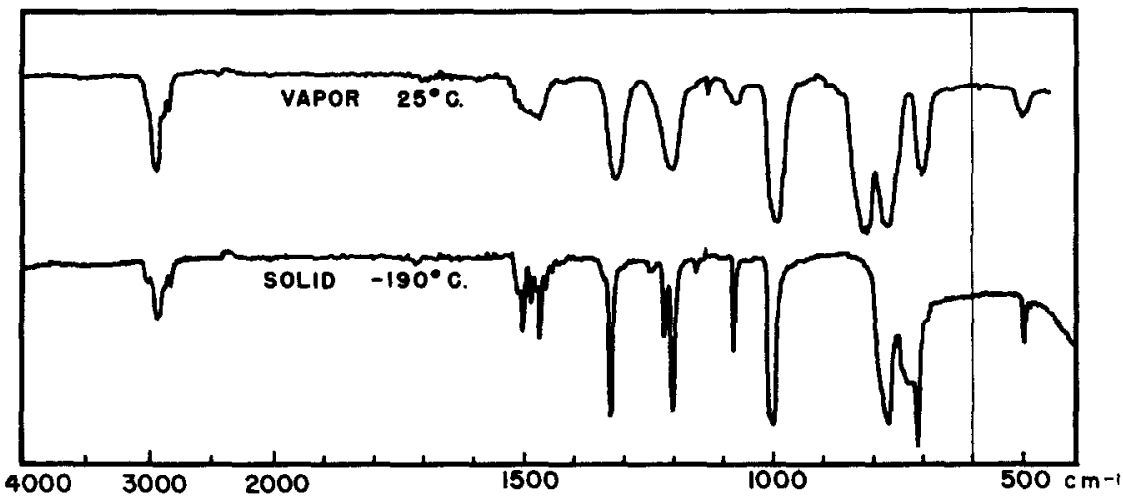

Fig. 1. Infrared Spectra of $\left(\mathrm{CH}_{3}\right)_{2} \mathrm{NPF}_{2}$.

and assignments. Figure 1 shows typical infrared spectra of dimethylaminodifluorophosphine in the vapor state at room temperature and as a solid at $-190^{\circ} \mathrm{C}$. The Raman spectrum of the liquid at $-70^{\circ} \mathrm{C}$ is shown as a microphotometer tracing in Fig. 2.

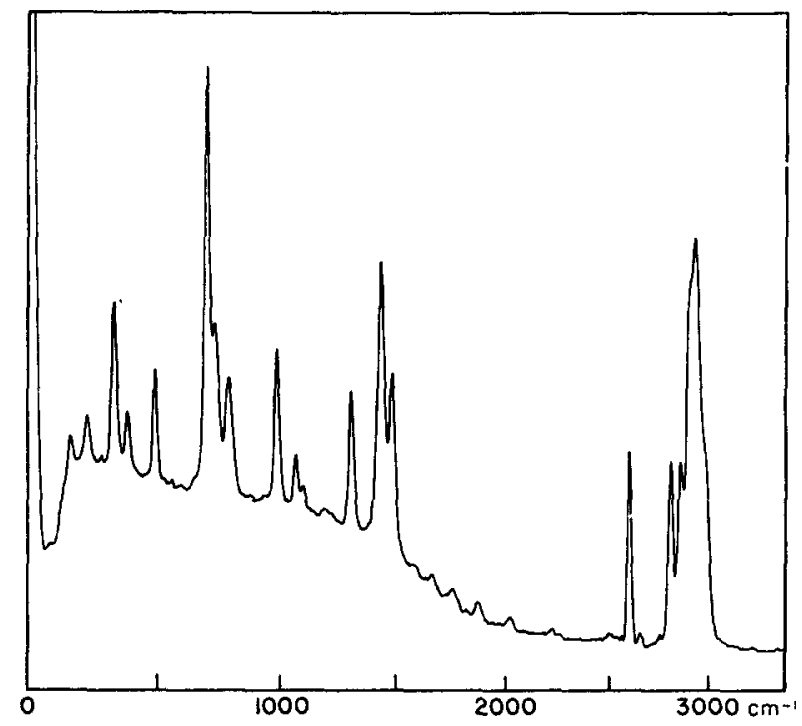

Fig. 2. Raman Spectrum of Liquid $\left(\mathrm{CH}_{3}\right)_{2} \mathrm{NPF}_{2}$ at $-70^{\circ}$.

\section{Renults and Discussion}

No structural data for this molecule have been published but chemical reasoning argues that the pyramidal arrangement of bonds around both the nitrogen and phosphorus found in $\left(\mathrm{CH}_{3}\right)_{3} \mathrm{~N}$ and $\mathrm{PF}_{3}$ is retained. $*$ However, the relative orientation

* Indirect evidence favoring a non-planar structure for the $\mathrm{C}_{2} \mathrm{NPF}_{2}$ skeleton has been obtained from the spectrum of the Lewis complex of $\left(\mathrm{CH}_{3}\right)_{2} \mathrm{NPF}_{2}$ with $\mathrm{BH}_{3}$. The frequencies of the free buse are shifled relatively lithle in the complex, an ulsservation cunsistent with a pyramidal arrangement around the phosphorus, the site of bonding. If the free base were planar, complexing undoubtably would distort it into a non-planar configuration and a much more marked spectral difference would result than is observed. Results for Lewis complexes of $\left(\mathrm{CH}_{3}\right)_{2} \mathrm{NPF}_{2}$ will be reported separately. 
of the two ends of the molecule with respect to each other cannot be decided with any certainty. Clearly, the cis configuration appears least favored for steric reasons but no satisfactory choice can be made between the gauche (hydrazine-like) structure and the completely trans arrangement. The possibility of a labile equilibrium existing between the latter two forms appears eliminated by the spectra. Figure 1 shows the infrared spectra of the gas and of the solid at low temperatures. The presence of rotational isomers in equilibrium usually is revealed by the simplification of the spectra in the transition from the gas or liquid to the solid. In the present case, no significant change occurs, other than the normal increase in line sharpness, indicating an appreciable barrier to internal rotation around the $\mathrm{P}-\mathrm{N}$ bond.

Somewhat arbitrarily, the trans model having $C_{s}$ symmetry has been assumed for purposes of classification in the present work. The thirty normal vibrations of the molecule under this point group divide into sixteen $A^{\prime}$ and fourteen $A^{\prime \prime}$ modes. A qualitative description and the numbering system is given in Table 2. For simplicity in discussion, the fundamentals may be divided into two groups, one containing

Table 2. A description of the fundamental vibrations of $\left(\mathrm{CH}_{3}\right)_{2} \mathrm{NPF}_{2}$

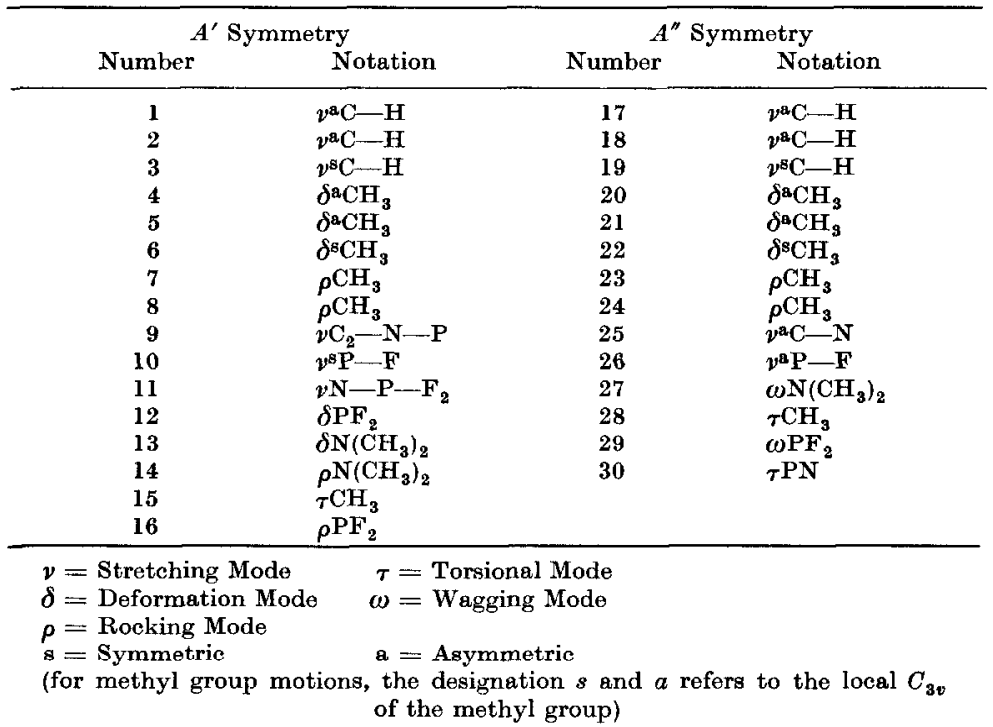

frequencies primarily associated with the methyl groups and the other with motions of the molecular skeleton. With one exception, no particular discussion of the methyl frequencies appears useful since they appear in the normal regions of the spectrum. Any assignments would to a large degree be arbitrary and subject to revision since considerable overlapping is present. The presence of a band at $2820 \mathrm{~cm}^{-1}$, however, is worth comment. SHEPPARD et al. [7], in a study of sixteen compounds containing the $=\mathbf{N}\left(\mathrm{CH}_{3}\right)$ group, observed that all contained a band in the $2760-2820 \mathrm{~cm}^{-1}$ region. This band, which presumably is a symmetric $\mathrm{C}-\mathrm{H}$ stretch, was further correlated by them with the presence of an unshared electron

[7] J. T. Braunholtz, E. Ebsworth, F. Mann and N. ShepPard, J. Chem. Soc. 2780 (1958). 
pair on the nitrogen since it disappeared upon salt formation or upon coordination of the nitrogen. The $2820 \mathrm{~cm}^{-1}$ band in the present case exhibited the same behavior and the usefulness of this observation for diagnostic purposes is accordingly extended.

The six-atom skeleton of dimethylaminodifluorophosphine should provide seven $A^{\prime}$ and five $A^{\prime \prime}$ frequencies all lying below about $1200 \mathrm{~cm}^{-1}$. These fundamentals are characteristic of the molecule and their correct assignment is important for the interpretation of the spectra of complexes in which $\left(\mathrm{CH}_{3}\right)_{2} \mathrm{NPF}_{2}$ acts as a base. Related molecules whose assignments are pertinent to the present work include dimethylamine [8], trimethylamine $[8,9]$, trifluorophosphine $[10,11]$ and dimethylaminodichlorophosphine [4].

The intense infrared bands at 814 and $770 \mathrm{~cm}^{-1}$ in the spectrum of the gas clearly are the two $P$ F stretching modes. Polarization data from the Raman effect indicate that the lower is the symmetric mode although the uncertainty associated with the measurement was higher than desirable for a clear choice. It is of interest to note that the position of these two bands shifted markedly and systematically to lower frequency in the transitions from gas to liquid to solid. None of the other frequencies showed an effect of the same magnitude, the shifts for the others at most being a few $\mathrm{cm}^{-1}$ as compared to about $50 \mathrm{~cm}^{-1}$ for the bands in question. Since the stretching frequencies of $\mathbf{P F}_{3}$ also show a marked shift to lower frequency in the transition from gas to liquid [12], a strong intermolecular interaction involving the $\mathrm{P}-\mathrm{F}$ bands must be present in the liquid state of these compounds.

The two other $A^{\prime}$ skeletal stretching modes can be described superficially as symmetric $\mathrm{C}-\mathrm{N}$ and $\mathrm{P}-\mathrm{N}$ stretches. The former is best identified with a band at $989 \mathrm{~cm}^{-1}$ despite the fact that its polarization state in the Raman effect is uncertain and it is significantly higher than the assigned symmetric $\mathrm{C}-\mathrm{N}$ mode in both diand trimethylamine. BeLLAMY [13] considers a band in this region to be characteristic of the $\left(\mathrm{CH}_{3}\right)_{2} \mathrm{NP}$-group and its failure to agree more closely with the corresponding amine frequencies probably is due to the normal coordinate containing an appreciable admixture of the $\mathrm{P}-\mathrm{N}$ stretch. Attempts to identify a characteristic $\mathrm{P}-\mathrm{N}$ stretching frequency in other molecules [13] have not becn particularly successful, probably because it couples readily with other skeletal motions. Values in the region between $680-750 \mathrm{~cm}^{-1}$ have been suggested. The most intense Raman band (polarized) of $\left(\mathrm{CH}_{3}\right)_{2} \mathrm{NPF}_{2}$ falls at $705 \mathrm{~cm}^{-1}$ and probably involves a principal contribution from the $\mathrm{P}-\mathrm{N}$ stretching although clearly being a mixed mode. It is tentatively described as a symmetric $\mathrm{NPF}_{2}$ stretch.

The two $A^{\prime}$ scissors motions of the $\mathrm{NC}_{2}$ and $\mathrm{PF}_{2}$ end groups are assigned from a comparison with the symmetric deformation frequencies of $\left(\mathrm{CH}_{3}\right)_{3} \mathrm{~N}$ and $\mathrm{PF}_{3}$. The remaining two $A^{\prime}$ skeletal modes involving rocking motions of the same two end

[8] J. R. Barcelo and J. Bellanato, Spectrochim. Acta 8, 27 (1956).

[9] E. J. Rosendaum, D. J. Rubin and C. R. SANDberg, J. Chem. Phys. 8, 366 (1940).

[10] R. C. TAYLOR and T. C. Bissot, J. Chem. Phys. 25, 780 (1956).

[11] M. K. Wilson and S. R. Polo, J. Chem. Phys. 20, 1716 (1952).

[12] R. C. TAYLOR, unpublished Raman data.

[13] Bellamy, The Infrared Spectra of Complex Molecules (2nd ed.), p. 323, Wiley (1958). 
groups are not assigned due to lack of information; they probably are included among the low frequency Raman lines observed.

Of the $A^{\prime \prime}$ skeletal modes, the asymmetric $\mathrm{PF}_{\mathrm{2}}$ stretch has already been mentioned. The other asymmetric stretching mode involving the $\mathrm{NC}_{2}$ end group must lie in the region between 1000 and $1250 \mathrm{~cm}^{-1}$ but an unequivocal choice is difficult because of the presence of $\mathrm{CH}_{3}$ rocking modes in this region. The assignments of BarceLo [5] for free di- and trimethylamine place the asymmetric $\mathrm{C}-\mathrm{N}$ stretch for both molecules between 1025 and $1050 \mathrm{~cm}^{-1}$. However, STEwart [14], from a study of

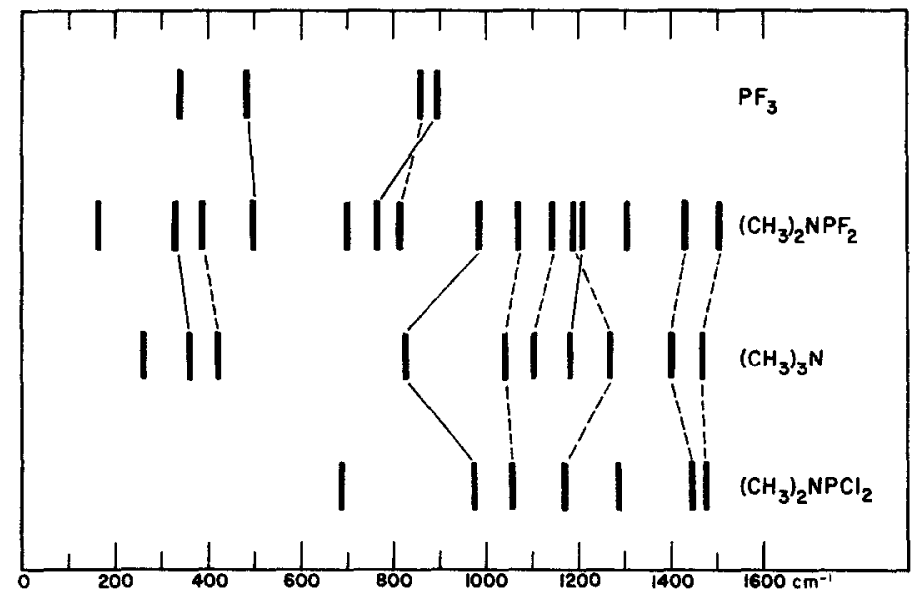

Fig. 3. Comparison of vibrational frequencies of $\left(\mathrm{CH}_{3}\right)_{2} \mathrm{NPF}_{2}$ and related compounds (in $\mathrm{cm}^{-1}$ ). — - Symmetric modes, - - - Asymmetric modes.

some thirty primary and secondary amines, assigns the asymmetric $\mathrm{NC}_{2}$ stretch to the region between 1140 and $1180 \mathrm{~cm}^{-1}$. Although a clear decision between the two choices cannot be made without spectra from the deuterated species and possibly a normal coordinate treatment, the higher value agrees better with data from analogous hydrocarbons and is given preference here. The remaining $A^{\prime \prime}$ skeletal modes involve wagging motions of the end groups and the torsional vibration around the $\mathbf{P}-\mathbf{N}$ axis. These fundamentals undoubtably are low in frequency and no secure basis exists at present for their assignment. The bar graph shown in Fig. 3 portrays the relationship of the frequencies of dimethylaminodifluorophosphine to those of trifluorophosphine, trimethylamine and the chloro compound.

Acknowledgement-This work has been supported by the National Science Foundation under Grant G-21408. In addition, one of us (M. A. F.) has been aided by a Public Health Service Fellowship (GPM-18006) from the Division of General Medical Sciences, Public Health Service. Mr. C. F. Farran obtained the Raman spectrum shown in Figure 2. This help is gratefully acknowledged.

[14] J. E. Stewart, J. Chem. Phys. 30, 1259 (1959). 